\title{
The influence of the media on COPD patients' knowledge regarding cardiopulmonary resuscitation
}

\author{
Stefano Nava' \\ Carmen Santoro' \\ Mario Grassi ${ }^{2}$ \\ Nicholas Hill ${ }^{3}$ \\ 'Respiratory Unit, Fondazione \\ S Maugeri, I R C C S Istituto \\ Scientifico di Pavia, Pavia, Italy; \\ ${ }^{2}$ Department of Health Sciences, \\ Section of Medical Statistics \\ and Epidemiology, University of Pavia, \\ Pavia, Italy; ${ }^{3}$ Pulmonary and Critical \\ Care Division, Tufts University, \\ New England Medical Center, Boston, \\ MA, USA
}

Background: The decision whether or not to undertake cardiopulmonary resuscitation (CPR) is a major ethical challenge. Patient preferences may be influenced by multiple factors, including information given by the media.

Objectives: We wanted to assess whether patients' knowledge about CPR survival and outcomes was related to presentation by the media.

Methods: 100 consecutive patients with COPD and chronic respiratory failure (CRF) and 100 patients at their first hospital admission for respiratory problems were enrolled. A questionnaire was administered to the patients seeking to ascertain their exposure to health information from the media, and to obtain their opinions on 1) the probability of survival after CPR, 2) the maximal length of time from collapse to CPR that allows a reasonable chance of survival, and 3) long-term outcomes of CPR survivors.

Results: The patients overestimated the success rate of CPR ( $63 \%$ of them estimated a hospital survival $>40 \%$ ), while the estimate of long-term outcome and timing of the procedure were more realistic. Bivariate correlations analysis showed significant correlation between the rate of correct responses and the viewing of educational television programs $(p=0.039)$, but not medical stories, reading of health-oriented newspapers, use of the internet, age, educational level, and the presence of CRF.

Conclusions: In conclusion, we have shown that both COPD and "newly admitted" patients' estimate of survival after CPR is much higher than reported by the current literature. A correct knowledge of CPR procedures and outcomes is significantly correlated with the exposure to "educational" medical TV programs, but not medical stories, newspapers, or internet sources. Keywords: cardiopulmonary resuscitation, chronic respiratory failure, chronic obstructive pulmonary disease, media, television

\section{Introduction}

The decision whether or not to undertake cardiopulmonary resuscitation (CPR) is one of the main ethical challenges in the intensive care unit (ICU). The recent International Consensus Conference on end-of-life care in the ICU (Carlet et al 2004) clearly advocated a shared approach to end-of-life decisions involving the patient, if competent, family and the caregiver team, with the aims of respecting the patient's autonomy and avoiding unwanted treatment.

Patient preferences may be influenced by multiple factors, including previous personal beliefs and experiences, discussions with clergy, friends, and healthcare professionals (Jones et al 2000) and last but not least, information derived from the media (Schowetter et al 1991, 1993). The increasing use of internet resources and television programs specifically dedicated to healthcare problems may have improved general knowledge about life-saving procedures. On the other hand, some media representations are not accurate, with some popular television programs showing much higher 
survival rates after CPR than the most optimistic reports in the medical literature (Diem et al 1996). Therefore, when physicians are discussing the use of CPR, both patients and their families may overestimate the success rate and therefore make biased decisions. As of yet, the question of how "old" (ie, TV, journals, and magazines) and "new" (ie, internet) media influence patients' perceptions about the success rate of CPR has not been examined. We prospectively assessed patient knowledge about CPR survival and outcomes in two groups of patients; one composed of chronically ill patients (ie, affected by COPD and chronic respiratory failure) and the other by a group of patients during their first hospital admission for an acute respiratory problem. We sought correlations with their perceived sources of media-derived health information.

\section{Material and methods}

The protocol was approved by the Institutional Ethical Committee and all enrolled subjects gave informed consent. We first developed a pilot questionnaire on 50 patients admitted to our Respiratory Unit. After reviewing and revising the questionnaire, we interviewed consecutive inpatients affected by COPD and on long-term oxygen therapy and patients admitted for the first time to our Unit for an acute respiratory problem. The aim was to collect complete data from 100 patients in each group. All the patients did not specifically address the problem of CPR in a previous hospital admission or with their GPs. Indeed none of them expressed formal "advance directives" since in Italy the legal context of end-of-life decision is very confused because of the lack of specific laws. The sample size was determined solving the formula of Withehead (1993) considering presence/absence of chronic respiratory failure with a study power of 0.90 and a significant level of 0.05 . The patients had a preliminary talk with the attending physician and head nurse about the nature of the questionnaire. At this stage, we clarified unclear concepts and responded to the patients' questions, but were very careful not to provide any information on the probability of CPR survival and outcomes.

Next, the patient responded to 3 sets of written questions. The first set ( $q 1-q 4)$ consisted of 4 ordinal questions rated from 1 to 5 points, designed to determine the patients' estimates of the probability of survival after CPR, the maximal length of time from collapse to CPR that allows a reasonable chance of survival and the potential for "normalization" of quality of life 12 months after CPR. The fourth question was a "control" question about the patients' understanding of CPR. In this set of questions, we used a pie chart showing different percentage ranges to determine the patients' estimates about CPR outcome.

The second set (q5-q8) consisted of 4 multiple choice questions about the type and frequency/month of exposure to media dealing with health-care. In particular, we investigated the role of fictional TV shows (ie, ER, and similar ones produced in Europe), TV educational programs, specialized publications and web-sites. The third set of questions queried patients on their education, their feelings about the reliability of the fictional medical shows and how they learned about the practice of CPR via the media. The questionnaire is presented in the appendix.

Threshold values for determining the rate of CPR survival (AHA et al 2000; Peberdy et al 2003), timing of intervention (ERC Guidelines 2000) and long-term outcomes (Gottschalk et al 2002; Van Alem et al 2004), were based on recent recommendations and meta-analyses.

Results are presented as frequencies and mean \pm standard deviation $( \pm \mathrm{SD})$ of number of right answers for the first set of questions.

Bivariate Pearson's correlations were performed to assess the association between the number of right answers to the first 3 questions and the frequency of media exposition. A multivariate regression analysis was also employed to correlate the correct answers with age, education, use of internet and the presence of chronic respiratory disease.

The SPSS v13.0 software was used for data analysis.

\section{Results}

A total of 236 patients were eligible and 200 completed the questionnaire. Thirty-six patients were unable to participate for the following reasons: lack of consent (18), psychiatric problems (7), incomplete questionnaire (6), and acute medical problems (5). Table 1 illustrates the characteristics of the 200 patients who completed the questionnaire, divided by the presence or absence of chronic respiratory disease.

Table 2 displays the distribution of answers for the questionnaire.

The respondents demonstrated a good understanding of CPR (q.4), overestimated the success rate of CPR, while the estimate of long-term outcome and timing of the procedure were more realistic. The statistical analysis showed significant correlations $(\mathrm{p}=0.039)$ between the rate of correct responses and the viewing of educational television programs (Table 3A), but none of the other variables, including education, age and type of disease (Table 3B). 
Table I Characteristics of the patients enrolled

\begin{tabular}{|c|c|c|c|}
\hline Variables & $\begin{array}{l}\text { COPD } \\
\text { patients } \\
(n .100)\end{array}$ & $\begin{array}{l}\text { First } \mathrm{H} \\
\text { admission } \\
\text { patients } \\
(\mathrm{n} .100)\end{array}$ & $\mathrm{p}$ value \\
\hline Age (yrs) & $58 \pm 12$ & $53 \pm 9$ & 0.23 \\
\hline $\operatorname{Sex}(M / F)$ & $53 / 47$ & $64 / 36$ & 0.15 \\
\hline Education (n. or \%) & & & 0.21 \\
\hline Grades I-5 & 43 & 47 & \\
\hline $6-8$ & 26 & 32 & \\
\hline College & 16 & 30 & \\
\hline Graduate school & 5 & 1 & \\
\hline Religion (n. or \%) & & & 0.53 \\
\hline Catholic & 76 & 84 & \\
\hline Agnostic & 10 & 8 & \\
\hline Other & 14 & 8 & \\
\hline Medical fictions on TV: ( $\mathrm{n}$ or \%) & & & 0.63 \\
\hline$>2$ times/month & 29 & 37 & \\
\hline$\leq 2$ times/month & 44 & 30 & \\
\hline Never & 27 & 33 & \\
\hline Educational program on TV: (n. or \%) & & & 0.66 \\
\hline$>2$ times/month & 30 & 36 & \\
\hline$\leq 2$ times/month & 32 & 33 & \\
\hline Never & 38 & 31 & \\
\hline Use of internet (n. or \%) & & & 0.065 \\
\hline Yes & 17 & 27 & \\
\hline No & 83 & 73 & \\
\hline General medical journals (n. or \%) & & & 0.96 \\
\hline$>2$ times/month & 14 & 11 & \\
\hline$<2$ times/month & 30 & 29 & \\
\hline Never & 56 & 60 & \\
\hline
\end{tabular}

Abbreviation: COPD, chronic obstructive pulmonary disease.
Seventy-four percent of the patients thought that fictional TV series were not representative of medical reality, and $76 \%$ reported obtaining information about CPR from the media.

\section{Discussion}

In his 1993 television interview with the BBC, Karl Popper stated that "The distinction between education and information is not only invalid, but also dishonest. There can be no information without a tendency ... we therefore need an institute for people who work in television like the institutes for doctors" (Popper 1993).

In order for patients to make sound medical decisions, medical information must be understandable and accurate. Patients' sources of information are multiple, however, including various forms of popular media. Schonwetter and colleagues (1993) found that $>90 \%$ of patients obtained information from television and $>70 \%$ from newspapers. But these sources are not always accurate; survival rates of CPR on the most popular fictional medical series on television have been shown to be significantly higher than the most optimistic survival rates in the medical literature (Diem et al 1996).

In addition, new sources of medical information have become available over the past decade, including medical websites for "nonspecialists" on the internet, and more and more television

Table 2 Distribution of answers to the questionnaire (see Appendix). Bold characters highlight correct answers

\begin{tabular}{|c|c|c|c|c|c|}
\hline \multicolumn{6}{|l|}{ Question } \\
\hline \#I & $0 \%$ & $<10 \%$ & $10 \%-40 \%$ & $40 \%-70 \%$ & $>70 \%$ \\
\hline Answers (\%) & $0 \%$ & $14 \%$ & $23 \%$ & $34 \%$ & $29 \%$ \\
\hline \#2 & $<3 \min$ & 3-6 min & $7-15 \mathrm{~min}$ & $15-30 \mathrm{~min}$ & $>30 \mathrm{~min}$ \\
\hline Answers (\%) & $26 \%$ & $38 \%$ & $22 \%$ & $8 \%$ & $6 \%$ \\
\hline \#3 & $<5 \%$ & $6 \%-20 \%$ & $20 \%-40 \%$ & $40 \%-60 \%$ & $>60 \%$ \\
\hline Answers (\%) & $3 \%$ & $11 \%$ & $19 \%$ & $16 \%$ & $51 \%$ \\
\hline$\# 4$ & I & 2 & 3 & 4 & 5 \\
\hline Answers (\%) & $71 \%$ & $3 \%$ & $14 \%$ & $7 \%$ & $5 \%$ \\
\hline$\# 5$ & Not at all & I or twice a month & $>$ twice a month & & \\
\hline Answers (\%) & $38 \%$ & $32 \%$ & $30 \%$ & & \\
\hline \#6 & Not at all & I or twice a month & $>$ twice a month & & \\
\hline Answers (\%) & $27 \%$ & $44 \%$ & $29 \%$ & & \\
\hline$\# 7$ & Not at all & I or twice a month & $>$ twice a month & & \\
\hline Answers (\%) & $56 \%$ & $30 \%$ & $14 \%$ & & \\
\hline \# 8 & Yes & No & & & \\
\hline Answers (\%) & $22 \%$ & $78 \%$ & & & \\
\hline \#9 & $\mathrm{I}-5$ & $6-8$ & College & Graduate school & \\
\hline Answers (\%) & $44 \%$ & $29 \%$ & $23 \%$ & $4 \%$ & \\
\hline$\# 10$ & Yes & No & Somehow & & \\
\hline Answers (\%) & $11 \%$ & $74 \%$ & $15 \%$ & & \\
\hline \#II & Personal & Friends & Clergy & Healthcare professional & Media \\
\hline Answers (\%) & $2 \%$ & $2 \%$ & $1 \%$ & $19 \%$ & $76 \%$ \\
\hline
\end{tabular}


Table 3A Pairwise Pearson's correlations coefficients, means and \pm SD of number of correct answers to the first 3 questions, and the exposure to media (number of educational TV programs, number of medical TV fictions and number of newpapers related to healthcare). $r$ values $>0.15$ are statistically significant $(p<0.05)$. The variable of internet use is not represented since it is not a numeric variable

\begin{tabular}{lllll}
\hline & Correct answers & Educational TV programs & Medical TV fictions & Health newspapers \\
\hline Correct answers & 1.00 & & & \\
Educational TV programs & 0.19 & 1.00 & 1.00 & 1.00 \\
Medical TV fictions & -0.02 & 0.44 & 0.33 & 0.57 \\
Health newspapers & 0.05 & 0.23 & 1.35 & 0.81 \\
Mean & 1.89 & 1.56 & 1.41 & \\
SD & 0.96 & 1.34 & \\
\hline
\end{tabular}

programs are specifically dedicated to healthcare. Whether all this increasing exposure to media sources of medical information could influence patients' perceptions of survival and outcomes of medical procedures like CPR remains unknown.

Our study demonstrates that patients are overly optimistic about survival rates after CPR. The large majority of the patients were exposed at least once a week to sources of medical information. Interestingly, they seem to be quite well aware (question \#10) about the distinction between fact and fiction, so that their knowledge about CPR was statistically correlated only to the viewing of "educational" programs that are presumably more accurate than fictional programs.

The internet, at least in Italy, is not actually a major source of information, since only a quarter or fewer of our patients were using it regularly, but this may be mainly dependent on the rather elevated age of the participants and on their low level of education. These two latter parameters were not, however, correlated with rate of correct answers.

Table 3B Regression coefficient of response variable

\begin{tabular}{lllll}
\hline Response variable & $\begin{array}{l}\text { Explanatory } \\
\text { variable }\end{array}$ & R coeff. & SE & p-value \\
& Sex & 0.14 & 0.15 & 0.359 \\
\hline Correct answers & Age & -0.02 & 0.07 & 0.792 \\
& Education & 0.00 & 0.08 & 0.994 \\
& Internet & -0.23 & 0.18 & 0.212 \\
& Respiratory failure & -0.08 & 0.15 & 0.570 \\
Educational TV programs & Sex & -0.14 & 0.22 & 0.538 \\
& Age & -0.06 & 0.10 & 0.555 \\
& Education & -0.12 & 0.11 & 0.269 \\
& Internet & 0.05 & 0.26 & 0.849 \\
Medical TV fictions & Respiratory failure & 0.06 & 0.22 & 0.765 \\
& Sex & -0.28 & 0.22 & 0.202 \\
& Age & 0.14 & 0.10 & 0.052 \\
& Education & -0.04 & 0.11 & 0.749 \\
& Internet & 0.07 & 0.27 & 0.796 \\
Health newspapers & Respiratory failure & 0.25 & 0.22 & 0.261 \\
& Sex & -0.05 & 0.13 & 0.672 \\
& Age & 0.01 & 0.06 & 0.871 \\
& Education & 0.02 & 0.07 & 0.813 \\
& Internet & 0.01 & 0.16 & 0.928 \\
& Respiratory failure & -0.08 & 0.13 & 0.547 \\
\hline
\end{tabular}

In our questionnaire we chose threshold values for determining the rate of CPR survival (AHA 2000; Peberdy et al 2003), timing of intervention (ERC Guidelines 2000) and long-term outcomes (Gottschalk et al 2002; Van Alem et al 2004), based on recent recommendations and meta-analyses. In addition, to avoid confusion, we focused our questions only on the acute care environment, which is more familiar to most patients. We also decided to study 2 different populations of patients (ie, COPD with chronic respiratory failure and first time admissions to the hospital), in order to assess the potential bias that frequent hospitalizations and the experience of a severe chronic disease might have had on the response rate. The two subsets of patients, even when the data were normalized for age and education, behaved very similarly. Also, question \#4 was added to assess patient comprehension of the CPR procedure. More than 70\% demonstrated a good understanding, as evidenced by a correct answer.

There are limitations to our study. First, it was performed in a single country and may not be generalizable. However, in the era of globalization, sources of information are rather homogeneous, since most of the "educational" programs are international formats and the main fictional programs are translated into several languages (ie, the most viewed programs in the questionnaire were ER and General Hospital). Second, we chose a visual representation in our questionnaire illustrating ranges of percentage rather than asking for simple numerical values (Murphy et al 1994). This was to reflect the healthcare literature, which usually provides ranges of survival and outcome after CPR.

In conclusion, we have confirmed that COPD and "newly admitted" patients' estimate of survival after CPR is much higher than reported by the current literature, but that of long-term outcome is more realistic. The most accurate answers were provided by those with the most exposure to educational TV formats, although this may reflect the greater interest and knowledge of the viewers than the educational value of the programs themselves. Nonetheless, our findings suggest that non-fictional educational programs are useful 
for dissemination of health care information to the public. Physicians discussing end-of-life decision with their patients should be aware that the media may be the major source of information or misinformation. Efforts should be made therefore to improve the patient/physician communication in order to get a more realistic vision of the end-of-life problems.

\section{Disclosure}

The authors have no conflicts of interest to declare.

\section{References}

[AHA] American Heart Association. 2000. Guidelines 2000 for cardiopulmonary resuscitation and emergency cardiovascular care. Circulation, 102(Suppl):I1-I384.

Carlet J, Thijs LG, Antonelli M, et al. 2004. Challenges in end-of-life care in the ICU. Intensive Care Med, 30:770-84.

Diem S, Lanton MPH, Tulsky JA. 1996. Cardiopulmonary resuscitation on television. Miracles and misinformation. $N$ Engl $\mathrm{J} \mathrm{Med}$, 334:1578-82.

[ERC] European Resuscitation Council. 2000. Guidelines 2000 for cardiopulmonary resuscitation and emergency cardiovascular care. Part I: Introduction to the international guidelines 2000 for CPR and ECC: a consensus of science. Resuscitation, 46:3-15.
Gottschalk A, Burmeister MA, Freitag M, et al. 2002. Influence of early defibrillation on the survival rate and quality of life after CPR in prehospital emergency medical service in a German metropolitan area. Resuscitation, 53:15-20.

Jones GK, Brewer KL, Garrison HG. 2000. Public expectations of survival following cardiopulmonary resuscitation. Acad Emerg Med, 7:48-53.

Murphy DJ, Burrows D, Santilli S, et al. 1994. The influence of the probability of survival on patients' preferences regarding cardiopulmonary resuscitation. N Engl J Med, 330:545-9.

Peberdy MA, Kaye W, Ornato JP, et al. 2003. Cardiopulmonary resuscitation of adults in the hospital: a report of 14720 cardiac arrests from the National Registry of Cardiopulmonary Resuscitation. Resuscitation, 58:297-308.

Popper K. 1993. Against television. BBC interview on April 13, 1993 [online]. Accessed on July 9, 2007. URL: http://www.mediamente.rai. it/mmold/english/bibliote/intervis/p/popper.htm\#link001.

Schowetter RS, Teasdale TA, Taffet G, et al. 1991. Educating the elderly: cardiopulmonary resuscitation decisions before and after interventions. J Am Geriatr Soc, 39:372-7.

Schowetter RS, Walker RM, Kramer DR, et al. 1993. Resuscitation decision making in the elderly: the value of outcome data. J Am Geriatr Soc, 8:295-300.

Van Alem A, de Vos R, Schmand B, et al. 2004. Cognitive impairment in survivors of out-of-hospital cardiac arrest. Am Heart J, 148:416-21.

Withehead J. 1993. Sample size calculations for ordered categorical data. Statistics in medicine 12:2257-71. 


\section{Appendix}

Question I: what is your estimated probability of survival after CPR performed inside the hospital by dedicated personnel?

$0 \% \quad<10 \% \quad 10 \%-40 \% \quad 40 \%-70 \% \quad>70 \%$

Correct: $10 \%-40 \%$ (ERC and AHA Guidelines 2000).

Question 2: what is the MAXIMUM time after a collapse to receive CPR in order to get your estimated probability of survival (see Question 1) and minimal permanent damage? $<3$ min 3-6 min 7-15 min 15-30 min $>30 \mathrm{~min}$ Correct: 3-6 min (Perberdy et al 2003).

Question 3: What is your estimated probability of returning to a normal life, without major cognitive or motor handicaps, 1 year after successful CPR?

$\begin{array}{lllll}<5 \% & 6 \%-20 \% & 20 \%-40 \% & 40 \%-60 \% & >60 \%\end{array}$

Correct: $>60 \%$ (Gottschalk et al 2002).

Question 4: What is CPR? (Choose one).

1. Use of artificial ventilation, cardiac massage, and eventually defibrillation after a collapse, an accident or acute medical illness leading to a cardio-respiratory arrest.

2. Use of powerful intravenous drugs after a collapse, an accident or acute medical illness leading to a cardiorespiratory arrest.

3. Use of defibrillator after a respiratory arrest.

4. Use of artificial ventilation in a patient that is short of breath.
5. Use of mouth to mouth ventilation alone after a collapse, an accident or acute medical illness leading to a cardio-respiratory arrest.

Correct: 1 (ERC Guidelines 2000).

Question 5: Do you watch "educational" medical TV programs?

Not at all Once or twice a month >twice a month Specify:

Question 6: Do you watch medical fiction programs on TV?

Not at all Once or twice a month >twice a month Specify:

Question 7: Do you read health-oriented newspapers?

Not at all Once or twice a month >twice a month Specify:

Question 8: Do you use internet for medical information?

Not at all Once or twice a month >twice a month Specify:

Question 9: What is your level of education?

Grades 1-5 6-8 College Graduate school

Question 10: Do you think that medical fiction program are reliable?

Yes No Somehow

Question II: How did you learn more about CPR?

Personal Friends Clergy Healthcare Media experience professional 